\title{
STUDENTS' SELF-EFFICACY OF NICENET IN EFL CLASSROOM
}

\author{
Anita Rezki \\ Institut Agama Islam Negeri Kendari \\ anita.rezki60@gmail.com
}

\section{ABSTRACT}

This study attempts to measure students' Self Efficacy in Nicent in EFL Classroom and to investigate whether or not there was any difference between male and female students. This study adopted a mixed method. Data gathered through a questionnaire, interview and relevant documents. The study was conducted in the English Language Education study program, in Halu Oleo University. Fifty students participated in this study by filling out a questionnaire, and eight students were interviewed to obtain more information related to their response to the questionnaire. Findings of the study indicate that students' self-efficacy were categorized into high level and average level. Regarding differences between male and female's self-efficacy in using Nicenet, the result of this study revealed no significant differences among them.

Keywords: Self-Efficacy, Nicenet, Technology Acceptance

\section{INTRODUCTION}

A number of researchers have conducted in the area of students' perception and online course by using Learning Management System (hereafter named LMS) (Jurczyk, Kushner Benson, \& Savery, 2004; Smart \& Cappel, 2006; Buzzetto-More, 2008; Lee \& Mendlinger, 2011; Fageeh, 2011; (Suharno \& Raharjo, 2014). Among the research, there is a lot of research found in the area of student's satisfaction perception. Nonetheless, it is important to bear in mind that the factors influencing the perception of satisfaction may vary among different countries and societies. This could lead us to suppose that their belief in their efficacy also may become one of the factors in learning. Arguing in a similar vein, Bandura maintains that people's belief in their efficacy influences their choices, aspirations, and the amount of effort they mobilizein a given endeavor (Bandura, 1997). Along with the above statement, Lee \& Mendlinger found that Computer/LMS Self-Efficacy is one of the key factors for the success of any online program (J.-W. Lee \& Mendlinger, 2011). It has a positive impact on behavioural intention toward online acceptance and satisfaction.

Furthermore, LMS self-efficacy is defined as self-assessment regarding one's skills using LMS, may be a critical factor in e-learner satisfaction (J.-K. Lee \& Hwang, 2007). Along with Lee \& Hwang, Eachus and Cassidy stated that self-efficacy is an important factor in understanding the frequency and success with which individuals use computers (Cassidy \& Eachus, 2002). Self-efficacy for technology use may be an important factor for student participation and performance. With courses being taught fully online or in hybrid settings (face-to-face and online), it has become important for students to be confident in their technology skills. Therefore, knowing whether the students have that confident in using technology is also needed for the lecturer or teacher to create the more effective class. 
Anita Rezki: Students' Self-Efficacy of Nicenet In EFL Classroom

In Halu Oleo University, LMS has been used for many years now. Particularly, Nicenet has been used in English Department since 2012 for several courses, such as CALL (Computer-Assisted Language Learning), Reading as well as writing. The students must join the class since it is a required course from the University. Both the students and the lecturers are new with Nicenet or any other LMS. However, there are also the lecturers who have used this LMS (Nicenet, Edmodo, etc.) since a couple of years ago.

Although this LMS has been used by several English lecturers in Halu Oleo University, only a little research and attention was devoted to students' perception of the system's acceptance, especially students' self-efficacy in using the computer or joining an online class in Nicenet. Therefore, this recent research will cover and investigate the self-efficacy of the students. Additionally, this recent research will only focus on Nicenet which has been used lately in English Department.

This proposed study is guided by several research questions as follows:

1. What is the level of students' Self-Efficacy toward Nicenet in English Department of Halu Oleo University?

2. Is there any difference in LMS Self-Efficacy regarding gender?

\section{LITERATURE REVIEW}

\section{Nicenet and Online Learning}

Nicenet ICA (Internet Classroom Assistant) is one of the popular LMS in online learning sector. This is proved by the latest information from Nicenet.org which shared that in the last month of January 2016, there are 9,956 users who have logged into the ICA, representing 1,941 active classes. Classroom in more than 25 countries at a wide range of age levels and disciplines use the ICA every week. Nicenet also receives over 100,000 individual page views per day. Nicenet also is a web-based tool for running an educational program at any level: a college course, a second-grade class, or a medical school course. This suggests us that there is no limitation or boundaries to everyone from every field who eager to use Nicenet as their online learning platform. Moreover, it has capabilities for two-way communication between members; for announcing schedules and schedule changes; for reminding you of tasks; for sharing useful web links with other members; and for submitting text information electronically. This implies that Nicenet is trying to provide their best services to whoever the user is (Mohamed \& Dzakiria, 2005; Goldsmith, 2010; Healey, 1998).

\section{Self-Efficacy}

Self-efficacy is broadly defined as the self-judgment of students regarding their capability for specific learning outcome. Bandura who is well-known as the pioneer of self-efficacy theory defined self-efficacy as beliefs in one's abilities to carry out a desired course of action (Bandura, 1997). According to Bandura, sources of self-efficacy and the self-beliefs of students are from mastery experience (performance on previous similar tasks); vicarious experience (modeling, or the observation of others' performance on similar tasks); verbal persuasion (feedback from significant others); and physiological and emotional reactions (e.g., anxiety) to specific tasks (Bandura, 1997). 
There are several sources of Self-Efficacy stated by Bandura. The explanation is shown below:

\subsection{Mastery Experience}

The case for the contextual role of self-efficacy in human behaviour can be made by exploring the four sources from which these beliefs are developed. The most influential source of these beliefs is the interpreted result of one's purposive performance or mastery experience. Bandura's emphasise that one's mastery experiences are the most influential source of self-efficacy information has important implications for the self-enhancement model of academic achievement, which contends that to increase student achievement in school, educational efforts should focus on altering students' beliefs of their self-worth or competence (Bandura, 1986).

\subsection{Vicarious Experience}

The second source of efficacy information is the vicarious experience of the effects produced by the actions of others. This source of information is weaker than the interpreted results of mastery experiences, but, when people are uncertain about their abilities or have limited prior experience, they become more sensitive to it. As Schunk has demonstrated, the effects of models are particularly relevant in this context. A significant model in one's life can help instil self-beliefs that will influence the course and direction that life will take (Schunk, 1981).

\subsection{Verbal Persuasion}

Individuals also create and develop self-efficacy beliefs as a result of the verbal persuasions they receive from others. These persuasions involve exposure to the verbal judgments that others provide and are a weaker source of efficacy information than mastery or vicarious experiences, but persuaders can play an important part in the development of an individual's self-beliefs (Zeldin \& Pajares, 2000).

\subsection{Physiological State}

Physiological states such as anxiety, stress, arousal, fatigue, and mood states also provide information about efficacy beliefs. Because individuals can alter their thinking, self-efficacy beliefs, in turn, also powerfully influence the physiological states themselves. Bandura has observed that people live in psychic environments that are primarily of their making. It is often said that people can "read" themselves, and so this reading comes to be a realization of the thoughts and emotional states that individuals have themselves created (Bandura, 1997).

It is important to restate that these sources of efficacy information are not directly translated into judgments of competence. Individuals interpret the results of events, and these interpretations provide the information on which judgments are based. The types of information people attend to and use to make efficacy judgments, and the rules they employ for weighting and integrating them, form the basis for such interpretations. Thus, the selection, integration, interpretation, and recollection of information influence judgments of self-efficacy.

\section{Self-Efficacy and Online Learning Acceptance}

As has been mentioned from the previous explanation about Self-Efficacy, it 
Anita Rezki: Students' Self-Efficacy of Nicenet In EFL Classroom

refers to an individual's belief that one caility ton perform a particular behaviour. Bandura defined self-efficacy as an individual's judgment of the individual's capabilities to organize and execute courses of action required to attain designated types of performances. He further stated that people's beliefs in their efficacy influenced their choices, their aspirations, and how much effort they mobilized in a given endeavour. Self-efficacy should not be considered as a measure of a specific skill because it concerns the extent to which individuals believe they can perform by using their skills. Thus, self-efficacy could be understood as a key mechanism that accounts for the interactive relationship between internal forces and external stimuli that affect human behaviour. Individuals who perceive themselves as highly selfefficacious tend to initiate a sufficient effort that may produce successful outcomes, whereas those who perceive low self-efficacy are likely to cease their efforts prematurely and fail in the task.

To the same extent, self-efficacy toward online learning, which is a situationspecific form of efficacy, refers to individuals' judgment of their capabilities to use online learning systems (including computers, the Internet, and web-based instructional and learning tools). Marakas, Yiand Johnson pointed out that there is a difference between task-specific and general self-efficacy (Marakas, Yi, \& Johnson, 1998). Marakas suggested that individuals who have high technology self-efficacy were more likely to report higher perceptions of usefulness and ease of use. Even for users with general self-efficacy, there may be a lack of task-specific self-efficacy (Marakas et al., 1998).

\section{METHODOLOGY}

This study adopted a mixed method design which employed both qualitative and quantitative research design. Instruments of the study were the questionnaire, interview guideline and relevant documents. The study was conducted in the English Language Education study program, in Halu Oleo Univesity, involving students who had joined and experienced the use of Nicenet in their class. Specifically, there were 50 subjects of this study gather from English Department of Halu Oleo University year 2012-2013 who already experience Nicenet for 1 and two years. The participants were asked to fill out the questionnaire, and eight students were interviewed to obtain more information related to their response in the questionnaire. Two kinds of questionnaires were used in this research; A demographic questionnaire which asks students' name, address, gender, age, academic class, etc. and LMS Self-Efficacy's questionnaire adapted from Mohamed and Karim (N. Mohamed \& Karim, 2012). Self-Efficacy questionnaire was piloted on Saturday, October $10^{\text {th }}, 2015$ and there are five questions are related to LMS SelfEfficacy.

Questionnaires were analyzed by using Descriptive Statistic (Frequency Analysis) by SPSS ver. 20, while the Interview and Open-Ended Question were analyzed through the qualitative way.

\section{FINDINGS}

Based on research questions, this section is divided into three sections. The first section presents the results about students' self-efficacy level in English 
Department of Halu Oleo University. The second section reported the results about students' differences in self-efficacy based on gender.

1. Self-Efficacy Level

In this instrument, there are five questions that represent the assessment of Self-Efficacy, especially Learning Management System's Self-Efficacy. The questions are asking about students' self-efficacy in resolving certain task by using Nicenet. After getting the information of students' Self-Efficacy to Nicenet, the score of their respond is categorized into a High, Medium and Low level. The scale was the selfextended scale from Brown.

Below is the result of data analysis:

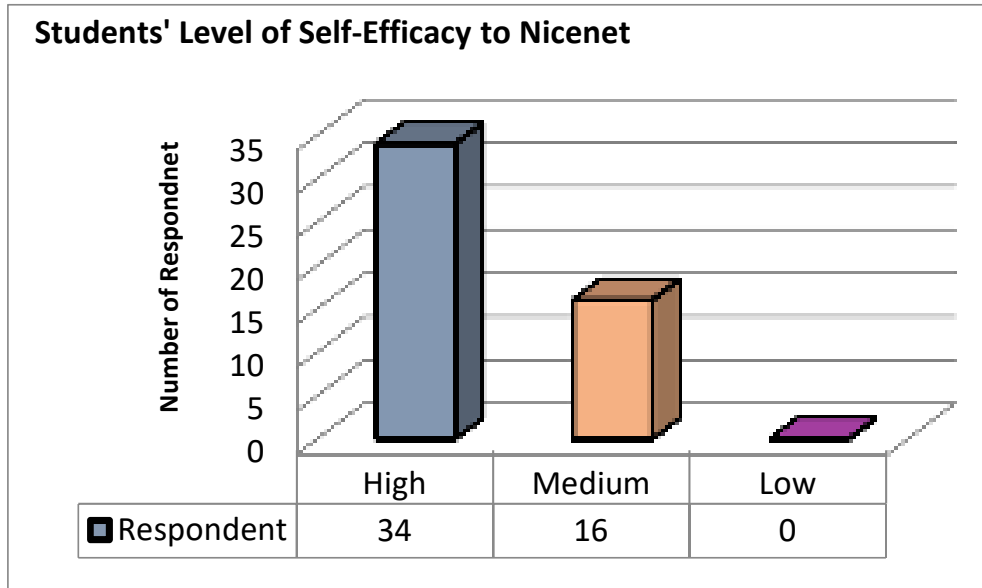

The graphic above informed us the general category for students' level of SelfEfficacy to Nicenet which become the first research question in this study. This result comes from the total scale category; 25-18 is categorized as High, 17-9 is categorized as Medium and 8-1 as categorized as Low Level. Regarding the result analysis (see Graph 4.1), 34 of 50 respondents categorized as High Self-Efficacy and the rest 16 respondents categorized as Medium level. However, there is no one who categorized to have low SE since the low score is in 15 which means far from low level higher standard. This may indicate as a good sign to the lecture as well because overall the students' tend to have a good Self-Efficacy in Nicenet specifically, and it is expected they also have a good sign in any other LMS given to them.

In analyzing Self-Efficacy matter, not only quantitative data was employed. The interview also conducted to obtain deeper information related to their perceived in Self-Efficacy. The question offered is related to their confidence in accessing Nicenet, Below is the detail coded in the transcripts:

Question:

"Do you feel confident when the first time trying Nicenet?"

"Because the mechanism is quite similar to opening blog, So I do not feel any difficulties and the lecturer also has already given the procedure to use Nicenet."

There are several of them who perceive that they feel confident when operating Nicenet since it is quite similar to Blog or any other LMS available that they have already used to support the distant learning. Meanwhile, there were 
Anita Rezki: Students' Self-Efficacy of Nicenet In EFL Classroom

several of them who still get confused to several features in Nicenet. Below is the response related to the case:

"The first time I use Nicenet, I was confident. However, there are some features that make me confused, such as the similar link name but it has a different function".

In the same vein, the other perceive the same feeling:

"At the first time, I was uncertain if I can do that. As the time pass by, I found it easy."

Based on the above transcript, the students may feel doubt when they use Nicenet for the first time. However, as the time passed by and after using for several times, they get used to it. Even though there are still some of them who get confused, they still feel confident in accomplishing any task given to them through Nicenet. Nicenet is not the matter anymore for them.

2. Analysis of Differences in Self-Efficacy based on Gender

In this section, it is displayed the result of research that had been conducted by the researcher toward fifty students as the research subject. The analysis of this gender matter refers to comparing the Mean score and the Independent Sample T-Test of SPSS Ver. 20. Below is the table of gender distribution

(Table 4.1 Gender Distribution)

\begin{tabular}{|c|c|c|}
\hline Gender & Frequency & Percentage \\
\hline Male & 17 & $34 \%$ \\
\hline Female & 33 & $66 \%$ \\
\hline
\end{tabular}

Based on the above table, from 50 respondents gather in this research, it was divided into 17 Male (34\% of the respondents) and 33 Female (66\% of respondents). However, this research only focuses on gender.

\subsection{Gender Matter}

Below is the result of Independent sample T-Test of Gender test regarding Self-Efficacy (SE).

\begin{tabular}{|llrrrr|}
\hline & Gender & N & Mean & \multicolumn{1}{c}{$\begin{array}{c}\text { Std. } \\
\text { Deviation }\end{array}$} & $\begin{array}{c}\text { Std. Error } \\
\text { Mean }\end{array}$ \\
\hline Total Self-Efficacy & Male & 17 & 18.35 & 1.967 & .477 \\
\cline { 2 - 7 } & Female & 33 & 18.88 & 2.522 & .439 \\
\hline
\end{tabular}

The effects of gender upon self-efficacy were examined using mean scores and standard deviations. Significant gender differences were found for self-efficacy. These differences indicate that Female rated in self-efficacy to use Nicenet slightly higher than Male. It can be proven by comparing their Mean Score. Female got slightly higher than Male; 18.88 for Female and 18.35 for Male. In conclusion, there is the difference between Female and Male regarding their self-efficacy.

However, the different result comes from Independent sample T-Test. In this result (see Table 5.8), the result shows that there is no significant result between Male and Female. 
Table 4.3 Independent Sample T- Test (Gender Test)

\begin{tabular}{|lllllr|}
\hline & & \multicolumn{2}{c}{$\begin{array}{c}\text { Levene's Test } \\
\text { for Equality of } \\
\text { Variances }\end{array}$} & $\begin{array}{c}\text { t-test for Equality of } \\
\text { Means }\end{array}$ \\
\cline { 2 - 6 } & F & Sig. & $\begin{array}{l}\text { Sig. (2- } \\
\text { tailed) }\end{array}$ & $\begin{array}{c}\text { Std. Error } \\
\text { Difference }\end{array}$ \\
\hline $\begin{array}{l}\text { Total Self- } \\
\text { Efficacy }\end{array}$ & Equal variances assumed & 1.152 & .288 & .457 & .702 \\
\cline { 2 - 6 } & $\begin{array}{l}\text { Equal variances not } \\
\text { assumed }\end{array}$ & & & .422 & .648 \\
\hline
\end{tabular}

This might happen since the result of Independent Sample T-Test refers to the general conclusion. Compared to the result of mean score who only have the slight difference, therefore, this result supports the result analysis of Mean Score. It indeed has no significant correlation, yet it is merely a slight difference between Male and Female regarding their Self-Efficacy of Nicenet.

\section{DISCUSSION}

Regarding discussion of this research, it involves more deep explanation about the data of students' self-efficacy, how they differ regarding gender to Nicenet as well as the limitations of this research.

1. Students' level of Self-Efficacy

Regarding the findings related to Self-Efficacy, it can be concluded that the respondent merely categorized into two types; High Level of Self-Efficacy (34 students) and Medium Level of Self-Efficacy (16 students). Moreover, in each question, more than half of the respondent response positively to each question of Self-Efficacy measurement. This might happen because of their mastery experience after using this system for around one year or 2 years in the different course in each semester. These findings is supported by Bandura (1986) who theorized that of four sources of Self-Efficacy (Mastery Experience, Vicarious Experience, Social persuasion and emotional states), mastery was the strongest predictor of self-efficacy. Based on the interview also revealed that they have already used Nicenet for several times, which indicates they have a lot of experience in using Nicenet.

However, based on the interview, their High and Medium Level of SelfEfficacy, as well as their positive response to each question, does not guarantee their interest to Nicenet. Once they felt excited, then easily get bored. This finding is different with the previous findings based on Lent who theorize that self-efficacy and outcome expectancies influence interests directly (Lent, Lopez, \& Bieschke, 1993). The effect of self-efficacy beliefs on an individual's interests has been widely 
Anita Rezki: Students' Self-Efficacy of Nicenet In EFL Classroom

researched. Results indicate strong support for the theorized relation between these constructs (Lapan, Boggs, \& Morrill, 1989; Schaub \& Tokar, 2005).

The assumption of why the questionnaire findings could be different with their interest to Nicenet is because of the overconfident matter. Stone in also found that a person that was over-confident in their abilities were high is self-efficacy and that these individuals also had less motivation and contributed less to reaching these goals (Stone, 1993). Therefore, the high level of students' self-efficacy will not guarantee their interest and performance in using system given to them.

2. Students' differences regarding gender

Regarding the findings of Gender Differences, this research found that there are no significant differences regarding gender in students' Self-Efficacy to Nicenet. This implies that even though there are no significant differences in gender, yet there are slight differences found after comparing each variable's Mean Score. The result of this study, however, has been inconsistent and research findings are inconclusive with regards to the effect of gender on this phenomenon. This finding seems to support the profile of contemporary undergraduates in the literature (Fulkerth, 1998; Green, 1999; Sax, Astin, Korn, \& Mahoney, 1998). Thus, this result may vary among different sample and subject.

\section{CONCLUSION.}

Based on the findings, data analysis, and discussion of this research, it could be concluded that students or the sample in this study are divided into two different level; High Level of SE and Medium Level of SE. These levels are considered as a good sign for students and the lecturer since it indicates that the students have their confidence in doing the certain task or any other specific matter to be accomplished by using Nicene as the media.

Moreover, the differences also come from another factor such as in gender. Even though the difference lies in gender is not significant, yet, this is still considered as the differences among the students. In conclusion, the result of this study reveals new information related to students' Self-Efficacy of Nicenet and the differences regarding gender. This result also found that questionnaire is indeed not enough to get students' deeper feeling to the certain situation. Therefore, interview also plays an important role to obtain deeper information

\section{REFERENCES}

Bandura, A. (1986). Social foundation of thought and action: A social-cognitive view. Englewood Cliffs.

Bandura, A. (1997). Self-efficacy: The exercise of control. Macmillan.

Buzzetto-More, N. (2008). Student perceptions of various e-learning components. Interdisciplinary Journal of E-Learning and Learning Objects, 4(1), 113-135.

Cassidy, S., \& Eachus, P. (2002). Developing the computer user self-efficacy (CUSE) scale: Investigating the relationship between computer self-efficacy, gender and experience with computers. Journal of Educational Computing Research, 26(2), 133153.

Fageeh, A. I. (2011). EFL learners' use of blogging for developing writing skills and 
enhancing attitudes towards English learning: An exploratory study. Journal of Language and Literature, 2(1), 31-48.

Fulkerth, B. (1998). A bridge for distance education: Planning for the information age student. Syllabus, 12(4), 28-30.

Goldsmith, J. (2010). NICENET: Free course hosting. LMS Web Site. DE Tools of the Trade.

Green, K. C. (1999). Campus Computing, 1998. The Ninth National Survey of Desktop Computing and Information Technology in American Higher Education.

Healey, D. (1998). Conferencing Online with Nicenet. English Language Institute Technology Tip of the Month: October 1998.

Jurczyk, J., Kushner Benson, S. N., \& Savery, J. R. (2004). Measuring student perceptions in web-based courses: A standards-based approach. Online Journal of Distance Learning Administration, 7(4).

Lapan, R. T., Boggs, K. R., \& Morrill, W. H. (1989). Self-efficacy as a mediator of investigative and realistic general occupational themes on the Strong-Campbell Interest Inventory. Journal of Counseling Psychology, 36(2), 176.

Lee, J.-K., \& Hwang, C.-Y. (2007). The effects of computer self-efficacy and learning management system quality on e-Learner's satisfaction. In Proceedings of the 2007 European LAMS Conference: Designing the future of learning (pp. 73-79).

Lee, J.-W., \& Mendlinger, S. (2011). Perceived self-efficacy and its effect on online learning acceptance and student satisfaction. Journal of Service Science and Management, 4(3), 243.

Lent, R. W., Lopez, F. G., \& Bieschke, K. J. (1993). Predicting mathematics-related choice and success behaviors: Test of an expanded social cognitive model. Journal of Vocational Behavior, 42(2), 223-236.

Marakas, G. M., Yi, M. Y., \& Johnson, R. D. (1998). The multilevel and multifaceted character of computer self-efficacy: Toward clarification of the construct and an integrative framework for research. Information Systems Research, 9(2), 126-163.

Mohamed, A. H., \& Dzakiria, H. (2005). Using NICENET in language classrooms at the Universiti Utara Malaysia, Malaysia. Malaysian Online Journal of Instructional Technology, 2(2), 114-123.

Mohamed, N., \& Karim, N. S. A. (2012). Computer Application Anxiety, Self-Efficacy and Open Source Learning Management System Acceptance. In Proceedings of the 12th WSEAS International Conference on Applied Computer Science, Singapore: WSEAS Press (pp. 274-278).

Sax, L. J., Astin, A. W., Korn, W. S., \& Mahoney, K. M. (1998). The American College Freshmen: National Norms for Fall 1998. Los Angeles: Higher Education Research Institute, University of California, Los Angeles.

Schaub, M., \& Tokar, D. M. (2005). The role of personality and learning experiences 
Anita Rezki: Students' Self-Efficacy of Nicenet In EFL Classroom in social cognitive career theory. Journal of Vocational Behavior, 66(2), 304-325.

Schunk, D. H. (1981). Modeling and attributional effects on children's achievement: A self-efficacy analysis. Journal of Educational Psychology, 73(1), 93.

Smart, K. L., \& Cappel, J. J. (2006). Students' perceptions of online learning: A comparative study. Journal of Information Technology Education, 5.

Stone, D. N. (1993). Overconfidence in initial self-efficacy judgements: Effects on decision processes and performance. BEBR Faculty Working Paper; No. 93-0121.

Suharno, A., \& Raharjo, K. (2014). K., \& Kertahadi.(2014). The Effect Of Computer Self-Efficacy Toward System Quality, Information Quality, Service Quality, Usage, User Satisfaction, And Individual Impact (A Study on University Students Using the E-Learning System at Kopertis III Jakarta). Journal of Information Engineering and Applications, 4(4), 31-41.

Zeldin, A. L., \& Pajares, F. (2000). Against the odds: Self-efficacy beliefs of women in mathematical, scientific, and technological careers. American Educational Research Journal, 37(1), 215-246. 